\title{
Development of optimum preplanning for maxillofacial surgery using selective laser sintering
}

\author{
L. Siva Rama Krishna ${ }^{1 *}$, Manmadhachary ${ }^{2}$, P. Bal Reddy ${ }^{3}$, Sriram Venkatesh $^{1}$ \\ ${ }^{1}$ Department of Mechanical Engineering, University College of Engineering, Osmania University, Hyderabad, INDIA \\ ${ }^{2}$ Department of Mechanical Engineering, National Institute of Technology, Warangal, INDIA \\ ${ }^{3}$ Department of Oral \& Maxillofacial Surgery, Govt Dental College \& Hospital, Osmania General Hospital, Hyderabad, INDIA \\ "Corresponding Author: e-mail: Isrkou@gmail.com
}

\begin{abstract}
Rapid prototyping is a technology that can automatically construct physical models from CAD data. It helps designers to quickly create tangible prototype of their design. This technology has numerous applications; they make excellent visual aids for communicating ideas to the customers. It plays an important role in producing complex and intricate models in both engineering and medical applications. This paper presents its application in medical field. It discusses the development of optimum preplanning for maxillofacial surgery using selective laser sintering process. It involves identifying the optimum value of various parameters like threshold value, gantry tilt angle, resolution, layer thickness and interval thickness of CT scan image. The 3D model of the CT scan image is developed and converted into .stl file. The 3D model is produced on Selective Laser Sintering machine by considering shrinkage and compensation allowances. Two case studies are presented and comparison is made with regard to time taken for surgery using RP model and without using RP model. This helps in reducing time and increase precision, as well as to decrease morbidity for maxillofacial surgery, thus resulting in less suffering to patient , thereby reducing costs and length of hospitalization and improving quality of life.
\end{abstract}

Keywords: Rapid prototyping, selective laser sintering, maxillofacial surgery, CT scanning, preplanning surgery.

DOI: http://dx.doi.org/10.4314/ijest.v3i8.16

\section{Introduction}

Rapid Prototyping (RP) is a technology that produces models and prototype parts from 3-Dimensionl (3D), Computer Aided Design (CAD) model data, Computer Tomography (CT), Magnetic Resonance Imaging (MRI) scan data, and model data created from 3D object digitizing systems (Pham, 1997). In additive fabrication, the machine reads the data from a CAD drawing and lays down successive layers of liquid, powder, or sheet material and builds up the model from a series of cross sections. The materials used in Rapid Prototyping are photo sensitive polymer resins, plastics, paper, ceramics, Aluminum, Copper, Stainless Steel, Titanium and Inconel. Based on the type of material used RP systems can be categorized into liquid-based, solid-based and powder-based. This paper focuses on selective laser sintering (SLS) method, which is a powder based RP system. SLS is a method of sintering and building up RP models by sintering the powder grains using $\mathrm{CO}_{2}$ laser beam.

Rapid Prototyping technology is applied in engineering and medical fields (Tukuru et al., 2008 and Gibson et al., 2004). It is helpful in engineering for product design, tooling and manufacture etc. RP medical applications are designing and development of medical devices, instruments, tissue engineering, teaching purposes, forensic pathology, prosthetics (Rahmat et al., 2010) and implantation. It is also helpful in planning of complex surgical operation (Drstvensek et al., 2008). This paper presents the development of optimum preplanning for maxillofacial surgery (Rosa et al., 2004 and Poukens et al., 2003) using SLS process. 
Traditional presurgical planning is based on the manipulation of 2-dimensional data obtained by radiography and photography. This approach has various problems. They limit the full appreciation of various bony structure movements. In traditional radiography we cannot know the exact extent of the disease. Appropriate surgical planning is difficult and time consuming. In radiography we cannot measure correct dimensions of anatomical structure. Reconstruction of surgical template cannot be accurate.

In today's maxillofacial surgery computer based treatment planning systems are available (Deran and Hirsch, 2009), for faster and more precise planning and reconstruction. In CT scan the anatomy of the human part is converted from analog to digital. From the CT examination, it is possible to narrow down the information by changing the Hounsfield units (HU) and creating a 3D reconstruction of the mandible. The 3D reconstruction is then converted into a polygon mesh that can be edited in a planning system. Several commercial systems are available. The benefit of a computer-based model compared to working with analog radiographs is to help doctors in visualizing the part in 3D space. The operation can also be revised without limitation. In introducing new technology in the field of maxillofacial surgery, this can be achieved by preoperative virtual planning of the reconstructive procedure in an advanced 3D environment and then bringing it to the operation theater.

Now a days, a maxillofacial surgical plan was designed virtually and produced on a rapid prototyping machine (Leiggener et al., 2009). The surgical planning steps and calculations were initiated by acquiring the patient's CT data sets from the maxillofacial, stored using Digital Imaging and Communications in Medicine (DICOM) as a medical image file format. The data were imported to the image processing software, which is used as an interactive tool for 3D visualization and segmentation of CT images. After segmentation, software converts the CT slices into a 3D surface model in Standard Triangle Language (STL) format. The transfer system is then manufactured using RP process. The optimal position and the angulations of the osteotomies and the length of the segments that have been agreed on were transferred to the RP sawing guide. The template is then positioned at the best specific anatomical location depending on the perforants and vascular pedicles.

The aim of this paper is to present the application of RP technology in maxillofacial surgery for reducing the time of surgery. This helps in minimizing the blood loss and reducing the suffering of the patient. Two case studies are presented on maxillofacial surgery; they are cyst in mandible and tumor in mandible.

\subsection{Cyst in mandible:}

It is a pathologic cavity or sac within the hard or soft tissues that may contain fluid, semi fluid or gas. It may be lined by epithelium, fibrous tissue or occasionally by neoplastic tissue. Initially cysts do not contain pus. It is when the cystic content becomes secondarily infected then the pus develops. Cysts may arise in any of the soft or hard tissues of the orofacial regions. The cyst part is shown in Figure 1 with a pointer.

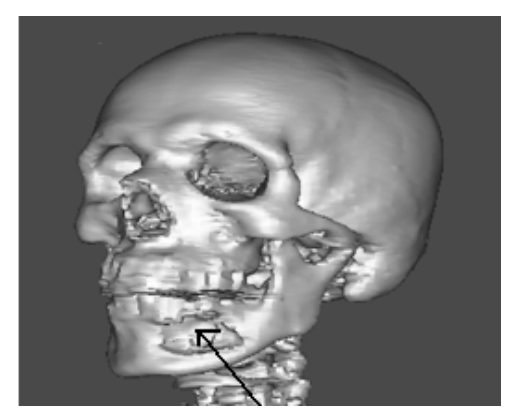

Figure 1: 3D reconstruction of Cyst in mandible using CT

\subsection{Tumor in mandible:}

Tumor or neoplasm's are new growths of abnormal tissue in the body. They are broadly divided into two groups benign and malignant depending upon their behavior pattern and cellular structure. A benign tumor grows slowly and is usually encapsulated. It enlarges by peripheral expansion and pushes away adjoining structure and exhibits no metastasis. However it may be locally aggressive. A malignant tumor, rapidly infiltrates the surrounding tissues, including vital structures and endangers the life of its host. In this study benign type of tumor in mandible is considered which is shown in Figure 2 with a pointer. 


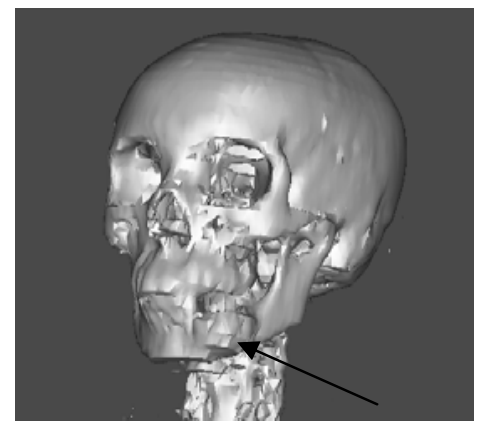

Figure 2: 3D reconstruction of Tumor in mandible using CT

\section{Problem Description}

Computer based treatment planning systems and rapid prototyping for maxillofacial surgery has few problems they are: while doing the CT scan it forms anatomy model layer by layer. These layers will overlap one over the other resulting in an unclear CT image. The factors affecting in unclear CT scan image are layer thickness, layer spacing, and layer formation. The layer formation depends on gantry tilt angel and threshold value. The 3-D model is created by converting DICOM images. The accuracy of DICOM image depends on resolution of image matrix and threshold value conditions. The major factors affecting the dimensional accuracy of RP model as compared to patient mandible dimensions using SLS RP process are shrinkage of RP material (Senthilkumaran et al., 2008; Yang et al., 2002) and part orientation. The objective of this paper is to minimize the above problems for preplanning operation of maxillofacial surgery. Two case studies are presented for on maxillofacial surgery; they are cyst in mandible and tumor in mandible.

\section{Methodology}

3.1 Preplanning operation of maxillofacial surgery using RP model: The following steps are involved to make 3D RP model for maxillofacial surgery (Milovanovic and Trajanovic, 2007; Singare et al., 2004):

- $\mathrm{MRI} / \mathrm{CT}$ data acquisition

- Creating a CAD model

- $\quad$ Convert the CAD model into STL format

- Slice the STL file into thin cross-sectional layers

- Construct the RP model one layer atop another

- Preplanning surgery on RP Model

3.1.1 MRI/CT data acquisition: In this step the data related to the anatomical structure and abnormalities are obtained from CT and MRI images. CT data is most suitable for modeling bone structures whereas the MRI data is best suited for modeling of soft tissues. DICOM images are generated in this stage. In this present work CT images of cyst and tumor in mandible are used to produce RP model.

3.1.2 Create a CAD model: For reconstructing the primary 3D anthropometrical model (bone structure and encapsulated soft tissues), the DICOM images obtained from the previous stage are converted into 3D CAD Model by using any imaging density segmentation software’s such as Materialize Interactive Medical Image Control System (MIMICS ${ }^{\circledR}$ ), 3D Doctor ${ }^{\circledR}$, Dental Vox ${ }^{\circledR}$, VG Studio Max $^{\circledR}$ etc.

3.1.3 Convert the CAD model into STL format: A standard interface is needed to convey geometric description from CAD packages to RP systems. The STL file was a standard has been used in many, rapid prototyping systems. Here MIMICS ${ }^{\circledR}$ software is used for converting into .stl file.

3.1.4 Slice the STL file into thin cross-sectional layers: After completing STL file conversion from CAD file, the file is sliced and imported to the RP machine. The slicing can be done using software's like MAGICS ${ }^{\circledR}$, EOS RP tool ${ }^{\circledR}$ etc.

3.1.5 Construct the RP model one layer atop another: After completion of layer formation the next step is to build the model on RP machine. Various RP technologies may be adopted for building the model, they are Stereolithography apparatus (SLA), SLS, Fused Deposition Modeling (FDM) etc. 
3.1.6 Preplanning surgery on RP Model: Once the RP model is build the cyst or tumor part is removed by cutting it on the RP model. Next the titanium plate is fixed to the RP model. This helps the surgeon in reducing the surgery time by knowing how much part is to be removed from the mandible and the how much bending of the titanium plate is done before the operation. The cutting and fixing of the titanium plate on the RP model is illustrated in Figure 3.

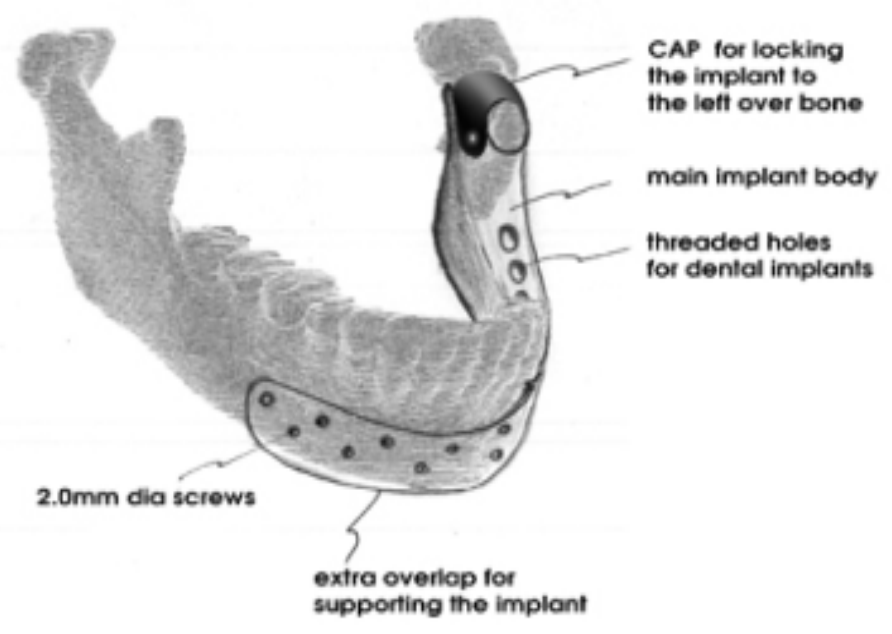

Figure 3: Arrangement of titanium plate on mandible of RP model

3.2 Factors effecting in CT data acquisition: In this step the data related to the anatomical structure and abnormalities of a mandible are obtained from CT images. Some of the factors that play a vital role in getting good quality CT data are: layer interval thickness, threshold value, resolution, and gantry tilt angle. They are discussed in detail in the following sections.

3.2.1 Layer thickness and layer interval thickness for CT data acquisition: CT imaging is sometimes compared as looking into a loaf of bread by cutting the loaf into thin layers. When the image layers are reassembled by computer software, they result in a very detailed multidimensional view of the body's interior. CT image layers are formed of an anatomy these layers overlap one over the other. The merged layers have some uniform interval this uniform interval is known as intervel thickness. The scan should be done with the same layer spacing, that must be less than or equal to the layer thickness.

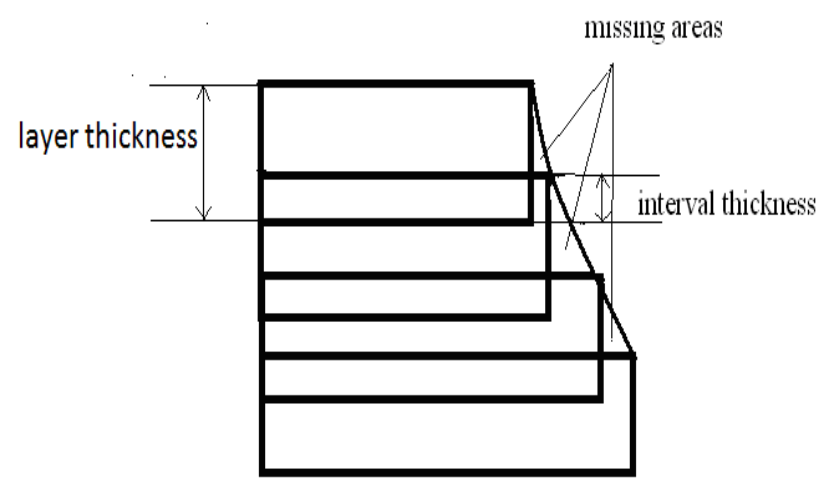

Figure 4: Layer formation and error formation in CT images

The formation of layers is shown in Figure 4. Due to merging of all these layers the edges of the anatomy are missing. The formation of layers and error is shown in Figure 4. When the layer thickens and interval thickness is low, the missing part of the anatomy is low. If the layer thickens and interval thickness is high, the missing part of the anatomy is also high. So to get optimum anatomy of CT image choose as much as possible minimum layer thickness and interval thickness.

In CT scan, the layer formation is one of the major problem. Generally while taking CT scan the radiologists adopt interval thickness as $1 \mathrm{~mm}$ and layer thickness as $5 \mathrm{~mm}$. Initially in this work, the RP model is produced using the above values. Actually 
this RP model should have a curved shape at the ridge part, but the ridge part obtained using the above values of layer thickness and interval thickness resulted in irregular shape as illustrated in Figure 5.

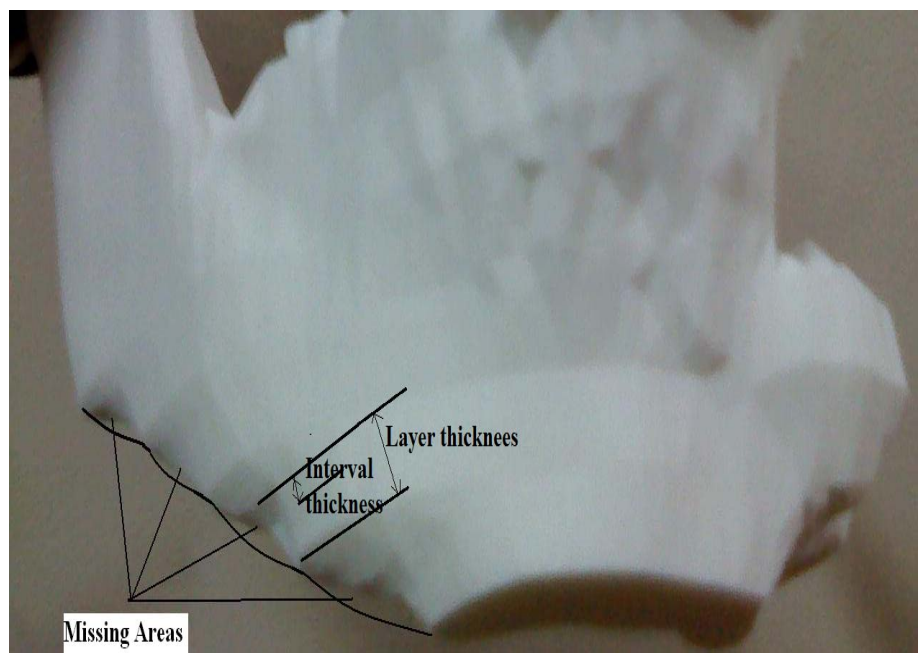

Figure 5: RP model of 5mm layer thickness and 1mm interval thickness

To avoid the above problem select as much as minimum values of interval thickness and layer thickness. While taking CT scan the optimums values are applied on CT machine this optimum values are varying in different CT machine. In this present work a layer interval thickness of $0.3 \mathrm{~mm}$ and layer thickness of $0.6 \mathrm{~mm}$ are considred.These values are optimums in 64 slice spiral CT machine. These minimum values are used to take CT scan and then the RP model is produced. Here it can be observed that the ridge part is curved shape and missing areas are almost negligible as shown in Figure 6 below.

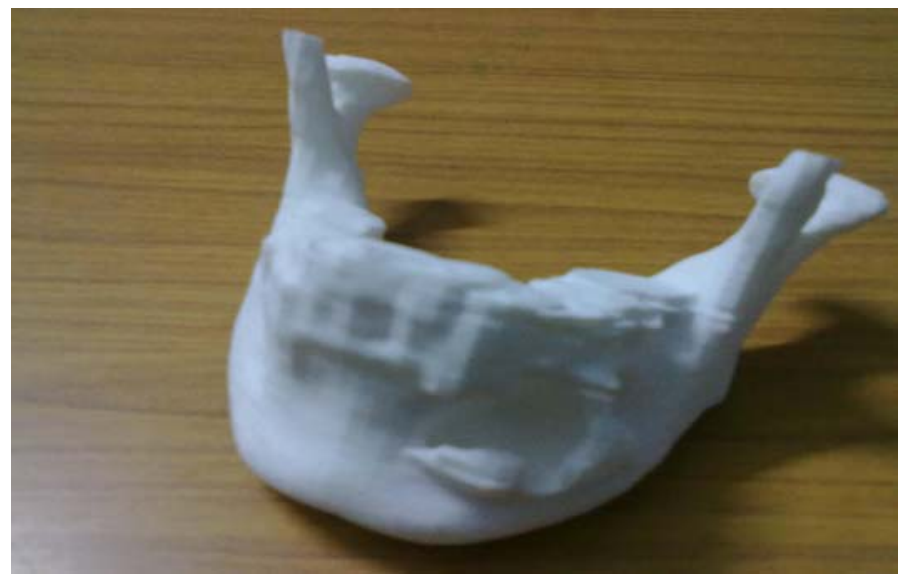

Figure 6: RP model of $0.6 \mathrm{~mm}$ layer thickness and $0.3 \mathrm{~mm}$ interval thickness

3.2.2 Threshold value for CT data acquisition: In this stage selecting a proper threshold value is an important task. Thresholding is the first action performed to create a segmentation mask on a set of digital images. A Region of Interest (ROI) can be selected by defining a range of grey values. A ROI can be selected by defining a range of CT values. The boundaries of that range are the lower and upper threshold values. The choice of the more appropriate threshold is done based on the Hounsfield Units of the tissue to be modelled. The Hounsfield Unit is used in medical imaging (CT scanning) to describe the amount of X-ray attenuation of each "voxel" (volume element). In the three-dimensional image, the voxels are normally represented as 12-bit binary numbers, and therefore have $2^{12}=4096$ possible values. These values are arranged on a scale from $-1024 \mathrm{HU}$ to $+3071 \mathrm{HU}$. On the basis of the tissue to be modelled a proper threshold value should be chosen corresponding to an appropriate CT number (HU). These values are shown in Table1. 

Vol. 3, No. 8, 2011, pp. 185-196

Table.1: CT number for various tissues

\begin{tabular}{|c|c|}
\hline Tissue & CT NUMBER (HU) \\
\hline Bone tissue & 1000 \\
\hline Liver & $40-60$ \\
\hline Whitematter (encephalon) & 46 \\
\hline Greymatter (encephalon) & 43 \\
\hline Blood & 40 \\
\hline Muscle & $10-40$ \\
\hline Kidney & 30 \\
\hline CSF(Cerbro-spinal Fluid) & 15 \\
\hline Water & 0 \\
\hline Fat & -50 to -100 \\
\hline Air & -1024 \\
\hline
\end{tabular}

In the present work the CT scan of the mandible is done which is a bone tissue, hence CT number of 1000 (HU) value is selected from Table 1.

3.2.3 Resolution for CT data acquisition: CT represents the finest resolution capability available in diagnostic systems achieving volumetric resolutions. The information from each plane can be put together to provide a volumetric image of the structure as well as the size and location of anatomical structures. Typical resolutions of the 2D-layers are $80 \times 80,160 \times 160,256 \times 256,512 \times 512$ or $1024 \times 1024$ pixels. Each pixel possesses an information depth of 8-bits. This pixels arrangement is illustrated in Figure 7.

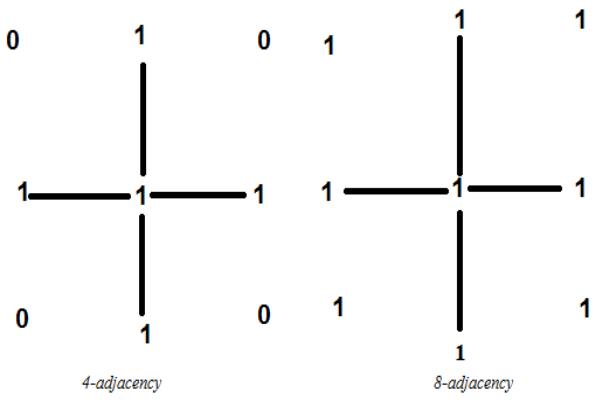

Figure 7: Arrangement of pixels

If the resolution of CT image is high, then the number of pixels is also high, so the CT scan image pixels will overlap with other pixels. If the resolution is less, the numbers of pixels will be low resulting in a blur image. Therefore the selection of resolution is very important. For acquiring accurate CT image, the CT-Scan data consisting of axial scan images of the entire anatomical organs is taken at $1 \mathrm{~mm}$ intervals at a resolution of $512 \times 512$ pixels, where each pixel size is $0.463 \mathrm{~mm}$.

3.2.4 Gantry tilt: In fact, this is also very important to know whether a patient has been scanned with a gantry tilt (an angulation of 0 degrees) or not. Although some of the dedicated software packages have been adapted to support data scanned with gantry tilt, interpolations and 3Dimensional representation will have an inferior quality due to the gantry tilt. The patient alignment with gantry tilt is shown in the Figure 8.

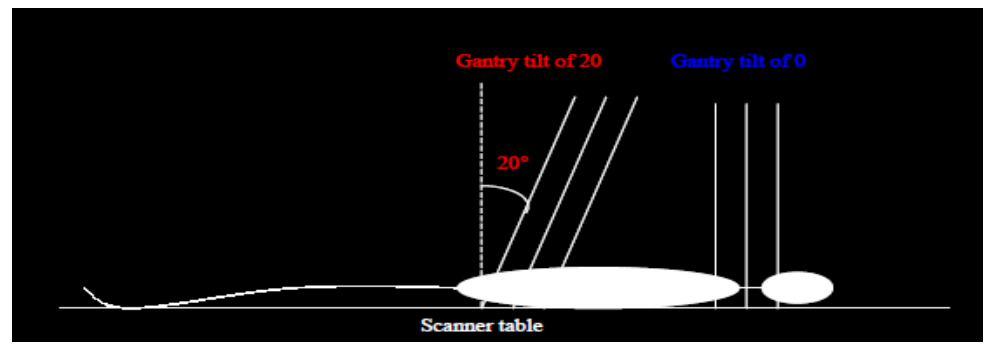

Figure 8: Patient alignment with gantry tilt 
By observing the layers it is clear that, without gantry the layer has some loss of anatomy, for prevention of this loss all these layers of the study should be scanned in the same direction i.e. $0^{\circ}$ as shown in Figure 9.

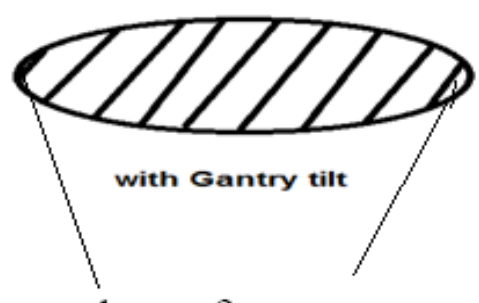

loss of areas

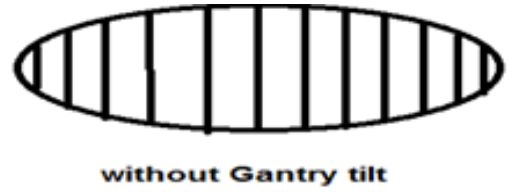

Figure 9: Layer formation of various gantry tilt

In the present work for get accurate RP model patient has been scanned with a gantry tilt.

3.2.5 Other precautions while taking CT data: Remove metal inserts, prosthesis, jewels to avoid scattering phenomena. This will reduce the risk of artefacts from the opposing jaw disturbing the images of the jaw of interest. In this present work the CT images are saved in the DICOM format which was developed by the National Electrical Manufacturers Association (NEMA) to aid the distribution and viewing of medical images, such as CT scans.

3.3 Create a CAD model: In this step the CT scan image saved in the DICOM format is imported into the RP software for building the 3D Model. In this present work, MIMICS RP software is used for creating the 3D model of the mandible. This is a powerful, easy, user friendly and fast 3D image processing tool. Within a few operations 2D images are transferred into a 3D model. It can import any 2D stack images like CT, TechCT, MRI, microscopy data and allow 3D reconstruction from them. Here applying threshold value plays a vital role for building an accurate CAD and constructing RP model.

Appling Threshold value in 3D software: In MIMICS to convert DICOM images to 3-D anatomy structure we have to choose the threshold value ranging from -1024 to +3071 , the 3-D model reconstruction stage is also subjected to errors. Selecting proper threshold value is an important step in this stage. The threshold value is selected in MIMICS ${ }^{\circledR}$ software based on the type of body part considered. For getting actual shape of the body part the threshold value selected is 0 . For nerves and soft tissues the threshold value is +86 . For hard tissues and bones structure the threshold value is +226 . To view inner holes the threshold value is +600 . In this present work, bone structure is considered having a threshold value of +226 .

3.4 Convert the CAD model into STL format: To get good quality STL file ensure that part is scaled in the CAD package before exporting to STL, to avoid a missing, degenerate, overlapping facet for sloping and curved surfaces. The STL file is saved in binary format instead of ASCII format because the file size increases when saved in ASCII format.

3.5 Slice the STL file into thin cross-sectional layers: After completing STL file conversion from CAD file next step is slicing the file. Slicing can be done using software's like MAGICS ${ }^{\circledR}$, EOS RP tool ${ }^{\circledR}$ etc. In this total object is divided into many number of slices. When producing the RP model the slice thickness is considered and the model is build with one slice over another slice. If the slice thickens is high, stair case effect (Sahatoo et al., 2008; Ancau and Caizar, 2008) will occur as shown in Figure 10. To get accurate RP model the stair case effect is minimised by using less slice thickness. In this work, a slice thickness of $0.1 \mathrm{~mm}$ is considered.
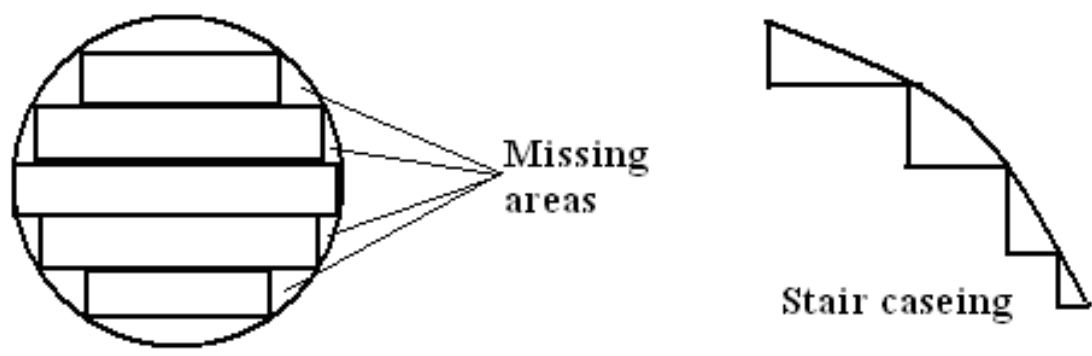

Figure 10: Stair case effect due to higher slice thickness 
3.6. Orientation of the part on RPT machine: Orientation of part on machine platform is an important factor to be considered. For achieving this in the present work, while taking CT scan of mandible it is ensured that the CT scan machine axes $(\mathrm{X}, \mathrm{Y}, \mathrm{Z})$ coincides with the RP machine platform axis, to avoid stair case effect.This is illustrated in Figure 11.

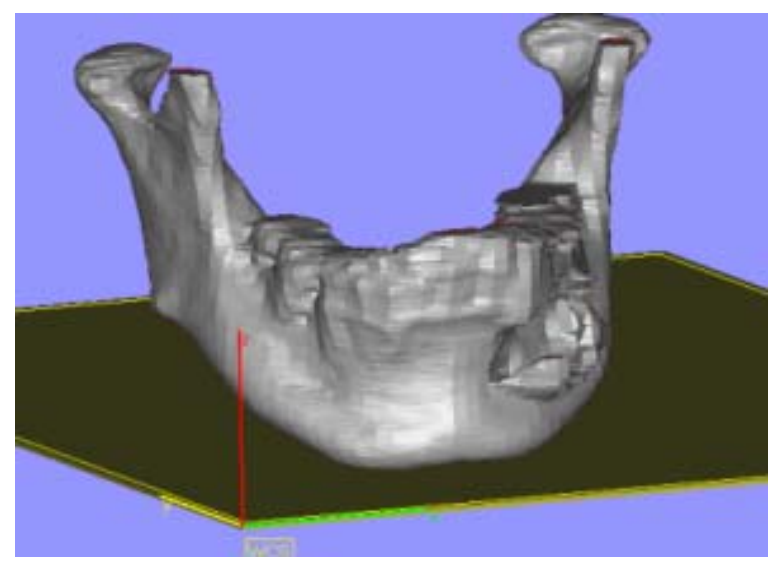

Figure 11: Orientation of part on RP machine

3.7 Preparing a prototype model on SLS machine: SLS is a RP process which can help in build parts with higher accuracy and also does not require any post curing operations. In this work the RP Model is build on FORMIGA P 100 SLS machine. The machine specifications are: build envelope (X) 200mm x (Y) 250mm x (Z) 330mm, layer thickness up to $0.1 \mathrm{~mm}$, laser type $\mathrm{CO}_{2}$, scanning speed $5 \mathrm{~m} / \mathrm{s}$, power supply 16A, compressed air supply 6,000 h/pa. While building the RP model of the mandible on the machine the various Allowances are considered which are discussed below:

3.7.1 Allowances in Rapid Prototyping: The allowances to be considered while developing the RP model are shrinkage allowances and compensation allowances.

In SLS process it is required that the temperature in the build chamber must be raised to just below the melting point of the powder under the nitrogen gas environment, for preventing the process from oxidation. Despite these conditions, thermal imbalance and shape distortion of SLS parts occur in the build chamber during the sintering process. The process is always accompanied by shrinkage as a result of thermal and phase change effects. In practice, the shrinkage is experimentally calibrated and the same is compensated during data preparation stage of rapid prototyping by scaling STL files. This is the representative phenomenon of shrinkage and curling that in turn severely influences the dimensional accuracy.

While taking CT scan, in DICOM images some part of anatomy is missing due to layer thickness and interval thickness, resulting in error of the RP model. This error is called compensation allowance. Reducing this error is important to get accurate dimensions. These allowances are reduced by scaling STL files.

In this paper both the above allowances i.e. shrinkage and compensation allowances are considered. These allowances have different values in each axis. Allowances in each axis are calculated to get exact dimensions of the prototype model, using the following mathematical relations:

Total absolute error $=$ shrinkage allowances of the prototype + compensation allowances due to CT image.

Shrinkage allowance $=$ Measurement in CAD model $(\mathrm{mm})$ - Measurement in Rapid Proto model $(\mathrm{mm})$

Compensation allowances $(\mathrm{mm})=$ Measurements in patient mandible $(\mathrm{mm})$ - Measurement in Rapid Proto model.

For calculating shrinkage allowance CAD model measurements are measured using CATIA Software. For this CAD model is saved in STL format in MIMICS software. This STL file is imported into CATIA software, in this required lengths are measured as shown in Figure 12 .For calculating compensation allowance, RP model measurements are measured using vernier callipers. In this work, the patient mandible measurements are measured using vernier calliper and steel rule as shown in Figure 12. 


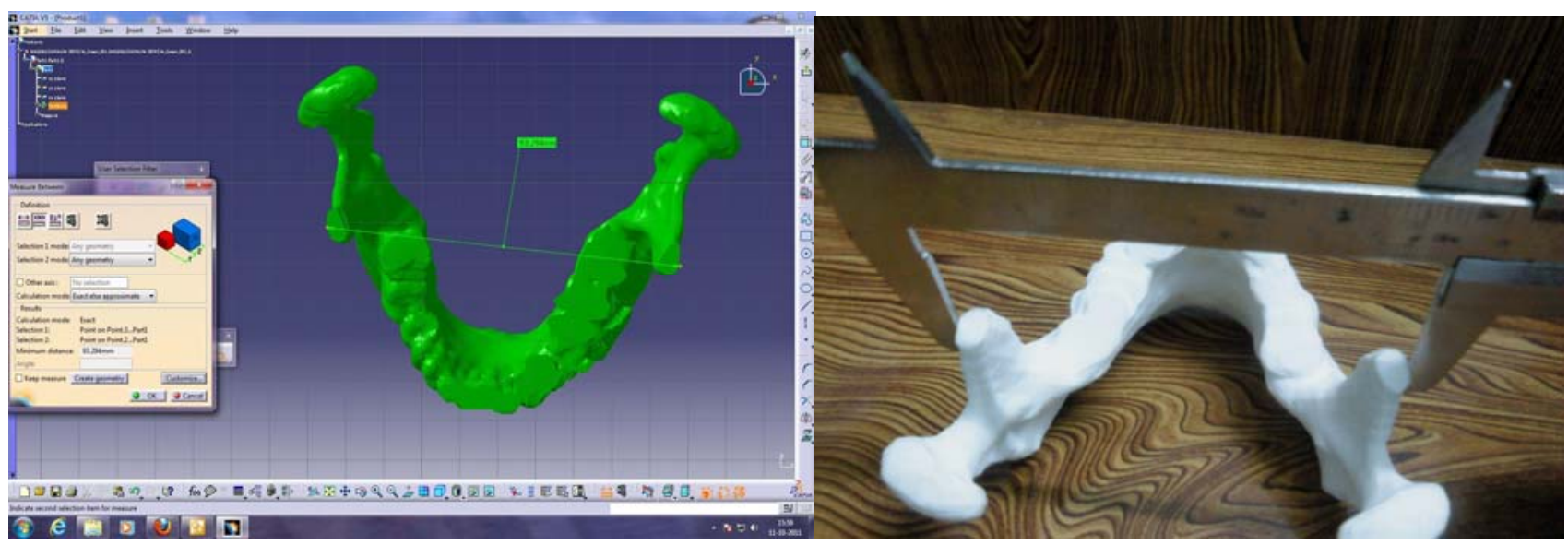

Figure 12: CAD model and Rapid Proto model Measurements are measured on CATIA \& Callipers

(Ibrahim et al., 2009) in their paper discuss the procedure for taking the linear measurements of the mandible. In the present work the procedure discussed by them is adopted. Figure 13 illustrates the linear measurements of mandible for finding the allowances (Ibrahim et al., 2009). Table 2, 3 and 4 shows the values obtained for shrinkage and compensation allowances obtained along X, Y and $\mathrm{Z}$ axis respectively.

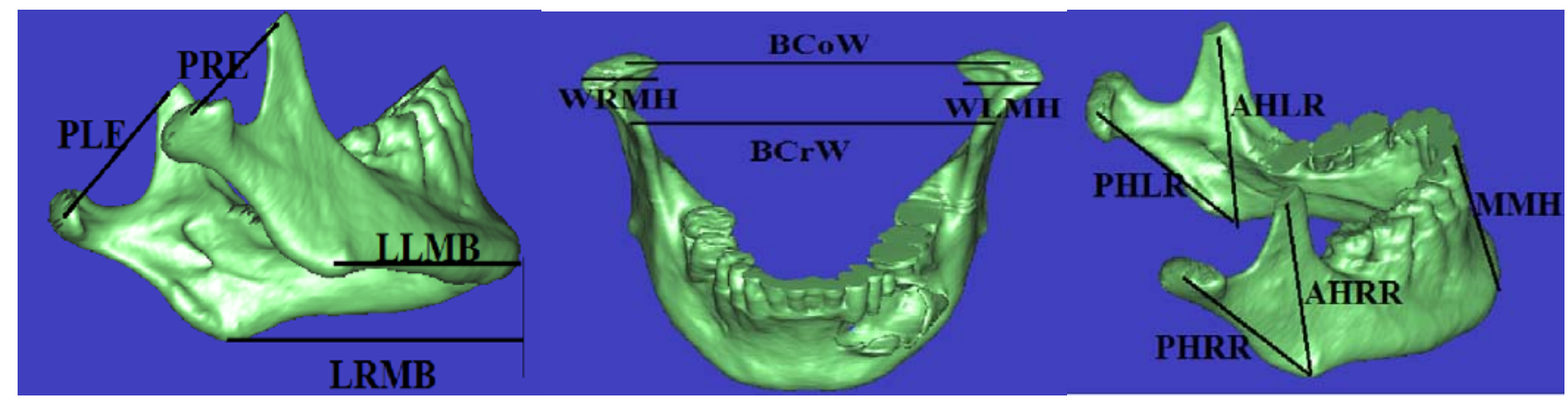

Figure 13: Linear measurements of mandible in X, Y, Z Directions

Table.2: Shrinkage and compensation allowances along X-axis ${ }^{*}$

\begin{tabular}{|c|c|c|c|c|c|}
\hline $\begin{array}{c}\text { Name of the } \\
\text { measurement }\end{array}$ & $\begin{array}{c}\text { Measurement in } \\
\text { CAD } \\
\text { model(mm) }\end{array}$ & $\begin{array}{c}\text { Measurement in } \\
\text { Rapid Proto } \\
\text { model(mm) }\end{array}$ & $\begin{array}{c}\text { Measurements in } \\
\text { patient } \\
\text { mandible(mm) }\end{array}$ & $\begin{array}{c}\text { shrinkage } \\
\text { allowances in } \\
\text { mm }\end{array}$ & $\begin{array}{c}\text { Compensation } \\
\text { allowances in mm }\end{array}$ \\
\hline BCrW & 93.29 & 89.92 & 91.06 & 3.37 & 1.14 \\
\hline BCoW & 96.62 & 93.4 & 94.88 & 3.22 & 1.48 \\
\hline WLMH & 23.85 & 20.64 & 21.87 & 3.21 & 1.23 \\
\hline WRMH & 23.72 & 20.28 & 21.87 & 3.44 & 1.59 \\
\hline
\end{tabular}

By the above table the average shrinkage value of $\mathrm{X}$-Axis is $3.31 \mathrm{~mm}$ and average compensation allowance is $1.36 \mathbf{~ m m}$.

Table.3: Shrinkage and compensation allowances along Y-axis ${ }^{*}$

\begin{tabular}{|c|c|c|c|c|c|}
\hline $\begin{array}{c}\text { Name of the } \\
\text { measurement }\end{array}$ & $\begin{array}{c}\text { Measurement in } \\
\text { CAD model } \\
(\mathrm{mm})\end{array}$ & $\begin{array}{c}\text { Measurement in } \\
\text { Rapid Proto } \\
\text { model }(\mathrm{mm})\end{array}$ & $\begin{array}{c}\text { Measurements in } \\
\text { patient mandible } \\
(\mathrm{mm})\end{array}$ & $\begin{array}{c}\text { Shrinkage } \\
\text { allowances in } \\
\mathrm{mm}\end{array}$ & $\begin{array}{c}\text { Compensation } \\
\text { allowances in mm }\end{array}$ \\
\hline LRMB & 75.48 & 72.16 & 73.4 & 3.32 & 1.24 \\
\hline LLMB & 75.85 & 72.44 & 73.63 & 3.41 & 1.19 \\
\hline PRE & 46.95 & 43.74 & 44.98 & 3.21 & 1.24 \\
\hline PLE & 50.13 & 46.95 & 48.26 & 3.18 & 1.31 \\
\hline
\end{tabular}

\footnotetext{
*Nomenclature is given at the end of the paper
} 
By observing the above table the average shrinkage value of $\mathbf{Y}$-axis is $\mathbf{3 . 2 8} \mathbf{~ m m}$ and average compensation allowance is $\mathbf{1 . 2 5} \mathbf{~ m m}$.

Table .4: Shrinkage and compensation allowances along Z-axis ${ }^{*}$

\begin{tabular}{|c|c|c|c|c|c|}
\hline $\begin{array}{c}\text { Name of the } \\
\text { measurement }\end{array}$ & $\begin{array}{c}\text { Measurement in } \\
\text { CAD model } \\
(\mathrm{mm})\end{array}$ & $\begin{array}{c}\text { Measurement in } \\
\text { Rapid Proto } \\
\text { model }(\mathrm{mm})\end{array}$ & $\begin{array}{c}\text { Measurements in } \\
\text { patient mandible } \\
(\mathrm{mm})\end{array}$ & $\begin{array}{c}\text { Shrinkage } \\
\text { allowances } \\
(\mathrm{mm})\end{array}$ & $\begin{array}{c}\text { Compensation } \\
\text { allowances in } \\
(\mathrm{mm})\end{array}$ \\
\hline AHRR & 59.88 & 57.76 & 58.66 & 2.12 & 0.9 \\
\hline AHLR & 58.81 & 56.56 & 57.36 & 2.25 & 0.8 \\
\hline MMH & 57.74 & 55.36 & 56.26 & 2.38 & 0.9 \\
\hline PHRR & 51.03 & 48.52 & 49.22 & 2.51 & 0.7 \\
\hline PHLR & 47.82 & 45.44 & 46.04 & 2.38 & 0.6 \\
\hline
\end{tabular}

From Table.4, it is observed that the average shrinkage values of Z-Axis is $\mathbf{2 . 3 2} \mathbf{~ m m}$ and average compensation allowance is $\mathbf{0 . 7 8}$ mm

By using the above values the RP physical model is built. Tables 5 and 6 illustrate the comparative time for preplanning surgery of the cyst in mandible and tumor in mandible with and without using RP model, after conducting the preplanning surgery at the department of oral \& maxillofacial surgery, Govt Dental College \& Hospital, Osmania General Hospital, Hyderabad, India.

Table.5: Comparison of time in maxillofacial surgery of cysts in mandible

\begin{tabular}{|c|c|c|}
\hline Tasks & $\begin{array}{c}\text { Time taken for } \\
\text { surgery without } \\
\text { using RP model } \\
\text { in minutes. }\end{array}$ & $\begin{array}{c}\text { Time taken for surgery } \\
\text { with using RP model } \\
\text { in minutes }\end{array}$ \\
\hline Bending of plate \& adaptation & 15 & 05 \\
\hline Grafting & 45 & 35 \\
\hline Remaining operation procedures & 15 & $\mathbf{5 5}$ \\
\hline Total time & $\mathbf{7 5}$ & \\
\hline
\end{tabular}

Table.6: Comparison of time in maxillofacial surgery of tumor in mandible

\begin{tabular}{|c|c|c|}
\hline Tasks & $\begin{array}{c}\text { Time taken for } \\
\text { surgery without } \\
\text { using RP model } \\
\text { in minutes. }\end{array}$ & $\begin{array}{c}\text { Time taken for surgery } \\
\text { with using RP model } \\
\text { in minutes }\end{array}$ \\
\hline Bending of plate \& adaptation & 20 & 10 \\
\hline Grafting & 50 & 40 \\
\hline Remaining operation procedures & 15 & 15 \\
\hline Total time & $\mathbf{8 5}$ & $\mathbf{6 5}$ \\
\hline
\end{tabular}

From Table.5 it is observed that the time reduction for cyst in mandible of maxillofacial surgery is 20 minutes. The operation time is saved by $\mathbf{2 6 \%}$ and from Table.6 it can be seen that the time reduction for tumor in mandible of maxillofacial surgery is 20 minutes. The operation time is saved by $\mathbf{2 3 \%}$. This results in less amount of blood loss, less suffering of the patient, less inflammation and postoperative pains, and finally less manipulation and suffering of the bone graft.

\section{Conclusions}

Rapid prototyping has got immense applications in the bio-medical field. The present work focuses on the development of optimum preplanning for maxillofacial surgery using SLS process. It involves identifying the optimum value of various parameters like threshold value, gantry tilt angle, resolution, layer thickness and internal thickness of CT scan image. A case study is presented and comparison is made with regard to time taken for surgery using RP model and without using RP model. For the case study considered, while taking CT image to get exact dimensions the values of layer thickness obtained is $0.6 \mathrm{~mm}$ and layer 
interval is $0.3 \mathrm{~mm}$, resolution $512 \times 512$ pixels each pixel being $0.463 \mathrm{~mm}$ and gantry tilt angle is $0^{\circ}$. The threshold value obtained for converting DICOM images to 3-D anatomy structure is +226. The shrinkage allowances obtained along various axis are: $\mathrm{X}$ Axis 3.31, Y-Axis 3.28, and Z-Axis is 2.32. The compensation allowances obtained are: X-Axis is 1.36 , Y-Axis is 1.25 and ZAxis is 0.7 . It is found that by using SLS Rapid Prototyping model $26 \%$ of time is saved while performing maxillofacial surgery of cyst in mandible and $23 \%$ of time is saved while performing maxillofacial surgery of tumor in mandible. Saving time means less suffering of the patient, less blood loss, less inflammation and postoperative pains, and finally less manipulation and suffering of the bone graft. The scope of the present work can be further extended by doing FEA analysis on the 3D CAD file for determining the stress on the bone structure at the cyst portion. This will help in determining whether the cyst part will withstand the externally applied load.

\section{Nomenclature [11]}

The nomenclature adopted by Ibrahim et al., (2009) for linear measurements were adopted in this work.

\section{Anatomical landmarks}

Alveolar crest (AC) - uppermost point of the alveolar crest between the alveoli of mandibular central incisors; Lateral condyle (LCo) - most lateral point of the head of the condyle, bilaterally;

Medial condyle (MCo) - medial point of the head of the condyle, bilaterally;

Upper condyle (UCo) - uppermost point of the head of the condyle, bilaterally;

Coronoid (Cr) -uppermost point of the coronoid process, bilaterally;

Gonium (Go) - lowermost and posterior point of the mandibular angle, bilaterally;

Mental (Me) - lowermost point of the middle line of the mandibular symphysis;

Pogonion (Pog) - most projecting median point of the mentum;

Linear measures

Anterior height of right ramus (AHRR) - distance from $\mathrm{Cr}$ to Go, right side;

Anterior height of left ramus (AHLR) - distance from Cr to Go, left side;

Median mandibular height (MMH) - distance from Me to AC;

Posterior height of right ramus (PHRR) - distance from UCo to Go, right side;

Posterior height of left ramus (PHLR) - distance from UCo to Go, left side;

Length of right mandibular body (LRMB) - distance from Go to Me, right side;

Length of left mandibular body (LLMB) - distance from Go to Me, left side;

Effective right mandibular length (ERML) - distance from UCo to Pog, right side;

Effective left mandibular length (ELML) - distance from UCo to Pog,left side;

Bicondylar width (BCoW) - distance between right and left UCo;

Bicoronoid width (BCrW) - distance between right and left Cr;

Width of right mandible head (WRMH) - distance from MCo to LCo, right side;

Width of left mandible head (WLMH) - distance from MCo to LCo, left side.

PRE - distance from AC to LCo, right side

PLE - distance from AC to LCo, left side

\section{Acknowledgement}

We thank the Director for Centre for Prototyping and Testing of Industrial products for allowing us to utilize the SLS machine for building the RP model. Our special thanks to the Head of the Dept. of oral \& maxillofacial surgery, Govt Dental College \& hospital, osmania general hospital, Hyderabad, India for giving the necessary medical inputs and carrying out the surgery using the RP model built in this project.

\section{References}

Ancau M., Caizar C., 2008. The optimization of surface quality in rapid prototyping. WSEAS International Conference on Engineering Mechanics, Structures, Engineering Geology (EMESEG '08).

Deran P., Hirsch J M, 2009. Virtual bending of mandibular reconstruction plates using a computer-aided design. International Journal of Oral and Maxillofacial Surgery, Vol 67, pp.1640-1643.

Drstvensek I., Hren N.I., Strojnik T., Brajlih T., Valentan B., Pogacar V., Hartner T.Z., 2008. Applications of rapid prototyping in cranio-maxilofacial surgery procedures. International Journal of Biology and Biomedical Engineering, Vol 2, No. 1.

Gibson I., Cheung L.K., Chow S.P., Cheung W.L., Beh S.L., Savalani M., Lee S.H., 2004. The use of rapid prototyping to assist medical applications”. Assises Europeennes de Prototypage Rapide, Vol 14. 
Ibrahim D., Broilo T.L., Heitz C., Oliveira M.G.D., Oliveira H.W.D., Nobre S.M.W., Filho J.H.G.D.S., Silva D.N., 2009. Dimensional error of selective laser sintering, three-dimensional printing and poly jet models in the reproduction of mandibbular anatomy. Journal of Cranio-Maxillofacial Surgery, Vol 37, pp.167-173.

Leiggener C., Messo E., Thor A., Zeilhofer H F., Hirsch J M., 2009. A selective laser sintering guide for transferring a virtual plan to real time surgery in composite mandibular reconstruction with free fibula osseous flaps. International Journal of Oral and Maxillofacial Surgery, Vol 38, pp.187-192.

Milovanovic J., Trajanovic M., 2007. Medical applications of rapid prototyping. Facta Universitatis Series: Mechanical Engineering, Vol 5, No 1, pp.79-85.

Pham D.T., Gault R.S., 1997. A comparison of rapid prototyping technologies. International Journal of Machine Tools \& Manufacture Vol 38, pp.1257-1287.

Poukens J., Haex J., Riediger D., 2003. The use of rapid prototyping in the preoperative planning of distraction osteogenesis of the cranio-maxillofacial skeleton. Computer Aided Surgery, Vol 8, pp.146 - 154.

Rahmat S., Farahmand F., Abbaszadeh F., 2010. Application of rapid prototyping for development of custom-made orthopedics prostheses: An investigative study. Majlesi Journal of Mechanical Engineering, Vol 3, No. 2, pp.11-16.

Rosa E.L.S.D., Oleskovicz C.F., Aragao B N., 2004. Rapid prototyping in maxillofacial surgery and traumatology: Case Report”. Braz Dent J, Vol 15, No. 3, pp. 243-247.

Sahatoo D.R., Chowdary B.V., Ali F.F., Bhatti R., 2008. Slicing issues in CAD translation to STL in rapid prototyping. IAJCIJME International Conference, Paper 021.

Senthilkumaran K., Pandey P.M., Rao P.V.M., 2008. Shrinkage compensation along single direction dexel space for improving accuracy in selective laser sintering. 4th IEEE Conference on Automation Science and Engineering Key Bridge Marriott, Washington DC, USA.

Singare S., Dichen L., Bingheng L., Yanpu L., Zhenyu G., Yaxiong L., 2004. Design and fabrication of custom made mandible titanium tray based on rapid prototyping. Medical Engineering \& Physics, Vol. 26, pp.671-678.

Tukuru N., Gowda K P S., Ahmed S.M., BadamiB S., 2008. Rapid prototype technique in medical field. Research J. Pharm. and Tech, Vol 1, No.4, pp.341-344.

Yang H.J., Hwang P.J., Lee S.H., 2002. A study on shrinkage compensation of the SLS process by using the Taguchi method. International Journal of Machine Tools \& Manufacture, Vol 42, pp.1203-1212.

\section{Biographical notes}

L. Siva Rama Krishna is currently working as Assistant Professor in the Department of Mechanical Engineering, University college of Engineering, Osmania University, Hyderabad, INDIA. He did his PhD in the area of Mechanical Engineering from JNT University, Hyderabad and M. Tech course in Computer Integrated Manufacturing from National Institute of Technology, Warangal. He has more than 19 years of experience in teaching and research. He has published more than 31 papers in various referred national and international conferences and journals. His research interests include CAD/CAM/CIM, operations management, manufacturing simulation and Rapid Prototyping. He has published a text book on Production Technology. He is a Member of Institute of Engineers (India) (MIE), Life Member of Indian Society of Technical Education (ISTE), and Life member of International Association of Engineers (IAENG).

Mr. Manmadhachary is currently working as Research Scholar in the Department of Mechanical Engineering, National Institute of Technology, Warangal. He did his B.Tech from Jawaharlal Nehru Technological University, Hyderabad and M.E in Production Engineering from University College of Engineering, Osmania University. He has done his M.E theses in development of optimum preplanning for maxillofacial surgery using selective laser sintering.

P. Bal Reddy received B.D.S from Osmania University in 1981, M.D.S from Mysore University in 1989, India. He is a Professor and H.O.D in the Dept of Oral and Maxillofacial Surgery, Govt Dental College \& hospital, Osmania General Hospital, Hyderabad, India. He has 21 years of experience in teaching and published many research papers both national \& international. He is also presented many research articles in conferences. His area of interest is in Laser application of maxillofacial surgery and selective laser sintering applications for preplanning of maxillofacial surgery.

Sriram Venkatesh is currently working as Professor in the Department of Mechanical Engineering, University College of Engineering, Osmania University, Hyderabad, INDIA. He did his Ph.D in the area of bulk solids flow problems from Osmania University, Hyderabad and M.E course in Tribology and Maintenance Engineering from Devi Ahilya Viswavidyalaya (SGSITS), Indore, M.P. He has more than 19 years of experience in teaching and research. He has been awarded "Career Award for Young Teachers" by All India Council for Technical Education, New Delhi, for his research contribution in the area of bulk solids flow problems. He is coordinator for various R\&D and consultancy projects and executed projects worth Rs. 50 Lakhs. Published over $\mathbf{5 0}$ papers in national \& international journal and conferences. He is member of many academic and professional bodies in India. He has visited Australia, USA, Germany, Singapore for presenting papers.

Received June 2011

Accepted January 2012

Final acceptance in revised form May 2012 